\title{
Empoderamento das mulheres quilombolas: contribuições das práticas mediacionais desenvolvidas na ciência da informação
}

\author{
Cleyciane Cássia Moreira Pereira \\ Doutoranda; Universidade Federal da Bahia (UFBA), Salvador, BA, Brasil; \\ cley.pereira20@gmail.com \\ Jaires Oliveira Santos \\ Mestranda; Universidade Federal da Bahia (UFBA), Salvador, BA, Brasil; \\ jairesoliveira@gmail.com \\ Maria Isabel De Jesus Sousa Barreira \\ Doutora; Universidade Federal da Bahia (UFBA), Salvador, BA, Brasil; \\ isasousa2010@ hotmail.com
}

\begin{abstract}
Resumo: O processo de mediação dentro das Comunidades Quilombolas constitui-se como elemento facilitador da inclusão social. São abordadas, tanto as atividades associativas das mulheres quilombolas de Itamatatiua, quanto o modo como práticas de interajuda africanas estão presentes nas relações sociais da população itamatatiuense diante dos recorrentes entraves políticos e econômicos. A presente revisão de literatura direcionou nossa reflexão a um consenso; o de que o processo de mediação da informação, objeto de estudo da Ciência da Informação, poderá auxiliar não apenas no empoderamento, mas também na conscientização dos indivíduos sobre sua própria força e poder de atuação em prol de sua inclusão social, contribuindo, dessa forma, para o protagonismo social dessas comunidades marginalizadas.
\end{abstract}

Palavras-chave: Ciência da Informação. Mediação da informação. Responsabilidade social. Comunidades quilombolas. Práticas associativas.

\section{Introdução}

Nas últimas décadas, a Ciência da Informação (CI) tem se preocupado em aplicar seus conceitos em direção ao contexto social das populações marginalizadas, permeadas pelas diversas modalidades de exclusão. Freire (2001) menciona que o principal desafio da área é, de fato, o de construir teias informacionais que trabalhem a favor da inclusão social. 
A literatura versa sobre a temática das práticas associativas ${ }^{1}$ adotadas pelas mulheres africanas frente ao contexto de pobreza, aplicadas na aquisição de bens, tanto materiais quanto imateriais, e recursos financeiros. Estão inclusos, por exemplo, os espaços de organização encontrados por essas mulheres, a partir de uniões solidárias, com a finalidade de reduzir as carências e buscar reconhecimento político, econômico e social.

Essas práticas associativas nos remetem a outras práticas cooperativas e associativas que as mulheres quilombolas de solo brasileiro têm buscado, a fim de reduzir a pobreza e melhorar suas condições de sobrevivência que, embora com contribuições advindas de programas governamentais, são insuficientes para atender as demandas sociais e informacionais.

Portanto, aprofundar o entendimento dessas práticas associativas, ainda que de contextos díspares, nos possibilita, através da potencialização dessas funções e atividades associativas, auxiliar na libertação e construção do empoderamento $^{2}$ da população quilombola. Isso porque, como menciona Casimiro (2010), as atividades associativas das mulheres africanas não auxiliam apenas em seu empoderamento econômico, satisfazendo não só suas necessidades básicas (alimentação, água potável, saúde, educação, habitação) como também informacionais, na perspectiva de promoção de melhoria de vida. Ou seja, a libertação que essas atividades proporcionam é promovida pela própria população. Freire (1983), por exemplo, aponta a educação libertadora como sendo um processo que só acontece quando o oprimido promove a sua própria revolução. Aqui, a inviabilidade de libertação que se percebe, procede dos diversos entraves decorrentes da execução de programas governamentais, e das amarras deixadas pelos opressores ao longo das gerações. Tais entraves contribuem para que as populações quilombolas carreguem em seu histórico os piores índices de pobreza, marginalizações e exclusões existentes em solo brasileiro.

Mediante esse contexto, defendemos que a CI possa, em parceria com as mulheres líderes e a partir da mediação de informação, auxiliar na identificação de informações que precisem ser trabalhadas nas práticas associativas, a fim de atribuir a essas mulheres maior independência dos programas governamentais, empoderando-as economicamente e fazendo-as donas de narrativas libertadoras. As- 
sim, as práticas de interajuda na obtenção de crédito, a partir das atividades associativas das mulheres africanas, podem se tornar um tema a ser aprofundado, trabalhado e adotado para a construção de um protagonismo e, também, como um auxílio na melhoria de vida da população quilombola do Brasil.

A revisão de literatura aqui adotada nos guiará na compreensão das práticas associativas das mulheres africanas, sobretudo naquilo que compreendem as pesquisas desenvolvidas por Casimiro (1999, 2010, 2011) e Gomes (2008). Para conhecimento acerca das práticas associativas das mulheres quilombolas, utilizaremos a pesquisa de campo realizada em 2010, pela pesquisadora (PEREIRA, 2011) ${ }^{3}$, na Comunidade Quilombola de Itamatatiua, situada no município de Alcântara, Maranhão.

Dessa forma, aprofundar o conhecimento a respeito dessas práticas associativas nos oferece, também, a possibilidade de melhor caracterizar o papel de liderança exercido pelas mulheres itamatiuenses, sujeitos da pesquisa intitulada Produção, acesso e uso da informação pelas mulheres quilombolas: o processo mediacional da Comunidade maranhense de Itamatatiua, desenvolvida no Curso de Doutorado no Programa de Pós-Graduação de Ciência da Informação da Universidade Federal da Bahia.

Nesse sentido, a presente comunicação abordará os conceitos e características socioeconômicas das comunidades quilombolas brasileiras, as práticas associativas exercidas pelas mulheres africanas embasadas nas práticas de interajuda mútua situadas dentro do contexto maranhense, a Comunidade Quilombola de Itamatatiua e as práticas associativas desenvolvidas por suas mulheres. Além disso, trataremos também de conceitos de Ciência da Informação que visam a mediação da informação com o propósito da redução dos bolsões de pobreza que atingem as Comunidades Quilombolas. E, por fim, são feitas algumas considerações que poderiam mediar as práticas em comunidades quilombolas.

\section{Comunidades quilombolas $\mathbf{x}$ mulheres africanas}

O conceito de "quilombo" provém do Século XVIII, quando, em 1740, o Conselho Ultramarino definiu quilombo como sendo "[...] toda habitação de negros 
fugidos, que passem de cinco, em parte despovoada, ainda que não tenham ranchos levantados e nem se achem pilões nele". (SANTOS, 2011). Esse conceito perpassava um sentido de proteção e refúgio a escravizados/as que requeriam proteção e abrigo. Esse conceito se modifica em etapas mais recentes, com a criação do artigo 68 da Constituição de 1988, no qual se inscreve que "[...] aos remanescentes das comunidades dos quilombos que estejam ocupando suas terras é reconhecida a propriedade definitiva, devendo o Estado emitir-lhes os títulos respectivos" (BRASIL, 2014, p. 157). Tal inscrição amplia a interpretação do conceito de quilombo para além de um espaço que abrigava negros fugitivos do período escravocrata, levando à compreensão de quilombo como um local de resistência das práticas culturais de um grupo segregado.

Como mencionado acima, o entendimento acerca das comunidades quilombolas se atualizou, tornando recorrente o reconhecimento de sua legitimidade não apenas nos meios rurais, mas também em contextos urbanos ${ }^{4}$. Com mais precisão, pode-se afirmar que são espaços que, após a Abolição da Escravatura, trazem em sua história as marcas da opressão e do abandono recriadas pela atualidade, abarcando os mais elevados índices de pobreza e exclusão sociais em terras brasileiras, ou seja, pessoas que vivem com menos de 70 reais mensais (INSTITUTO BRASILEIRO DE GEOGRAFIA E ESTATÍSTICA, 2013).

Por várias décadas, essas comunidades foram deixadas à margem. Só ressurgiram nas pautas das políticas públicas por conta das lutas e embates enfrentados pelos movimentos negros e seus intelectuais, sobretudo no final dos anos 80, quando o artigo 68 do Ato das Disposições Constitucionais Transitórias (ADTC) reconhece "Aos remanescentes das comunidades dos quilombos que estejam ocupando suas terras a propriedade definitiva, devendo o Estado emitirlhes os títulos respectivos", na promulgação da Constituição de 1988 (BRASIL, 2014, p. 157). Passados quase duas décadas, em 2004, para que os primeiros passos fossem dados em prol da execução dessa disposição, lançou-se o Programa Brasil Quilombola, integrando 21 órgãos da administração pública federal que passaram a administrar políticas públicas dirigidas em função do desenvolvimento das comunidades quilombolas. 
No Brasil, existem cerca de 2.474 comunidades quilombolas, sendo que 491 delas se encontram no Estado do Maranhão, que só fica atrás do estado da Bahia, que abarca 616 comunidades (FUNDAÇÃO CULTURAL PALMARES, $2015)^{5}$. É no Maranhão que se encontra a Comunidade de Itamatatiua, espaço que tomamos como território de investigação.

O Programa Brasil Quilombola foi lançado em 2004, após a criação da Secretaria Especial de Políticas de Promoção da Igualdade Racial (SEPPIR), com o objetivo de consolidar os marcos da política de Estado para as áreas quilombolas. Desmembrado na Agenda Social Quilombola (Decreto 6261/2007), que agrupa as ações voltadas às comunidades em áreas como: Acesso à terra; Infraestrutura e qualidade de vida; Inclusão produtiva e Desenvolvimento local e Direitos e cidadania (BRASIL, 2013); este programa representou uma nova fase na visibilidade dessas comunidades diante dos poderes públicos, no que se refere à criação e contemplação de políticas públicas aos descendentes dos negros escravizados. Contraditoriamente, os dados levantados pelo Governo Federal sobre estes programas evidenciam que, passados quase 10 anos, muitos aspectos permanecem praticamente inalterados, permeados por entraves de caráter administrativo e repasses orçamentários ínfimos, insuficientes para a erradicação das mazelas, pobreza e exclusões que há séculos vêm acometendo essas populações.

De acordo com um levantamento realizado pelo Ministério do Desenvolvimento Social (MDS), em 2011, existiam, no Brasil, 169 comunidades quilombolas que obtiveram título de posse coletiva da terra. As lideranças dessas comunidades reconheceram que houve melhorias em suas condições de sobrevivência após a titulação. Porém, ainda há muito por ser feito, diante do percentual de mais de $50 \%$ de adultos e crianças que ainda passam fome; dos mais de $76 \%$ de indivíduos sem acesso aos serviços de saneamento básico; enquanto, em 20\% das comunidades pesquisadas, faltam escolas primárias, escolas secundárias se fazem presente em apenas 9, 2\% destas; em 15\% destas comunidades não há agentes comunitários de saúde, considerados pelo PBQ a forma de assistência médica básica e de custo mínimo nessas localidades, ausência que também impossibilita o cadastro dessas famílias aos programas governamentais e, consequentemente, o recebimento de programas sociais (SUMÁRIO..., 2013). 
Outro dado que causa estranheza diante de tal levantamento refere-se à baixa produção e criação coletiva; enquanto cerca de $80 \%$ dos entrevistados mencionaram que sabiam de alternativas produtivas para as respectivas comunidades, apenas $21,1 \%$ tinham algum tipo de projeto coletivo, sendo a maioria por iniciativa própria, sem relações com os programas sociais. Segundo os participantes, a inviabilidade desses projetos deve-se a dois fatores: a "[...] falta de logística e assistência para elaboração dos projetos [...]" e a "falta de informação". (SUMÁRIO..., 2013, p. 6). Somam-se a essas questões os desvios de recursos e a ausência de parcerias entre o governo federal, estadual e municipal e as ONGs, problemas que vêm enfraquecendo e retardando o reconhecimento e avanços na qualidade de vida da população.

Ao ser questionado, em 2011, sobre os entraves da aplicação do orçamento do Brasil quilombola, Verdum explica que havia dificuldades estruturais, visto que:

[...] as políticas para as comunidades quilombolas dependem e muito do desempenho de secretarias estaduais, secretarias municipais; ONG; ou mesmo associações locais, criadas pelas próprias comunidades locais. Quando não há o compromisso político e falta interesse, só procedimento burocrático movendo as pessoas, tudo fica muito mais difícil. Em vários casos dar prioridade para essas comunidades é entrar em choque com interesses outros, que vêem no reconhecimento dos direitos das comunidades quilombolas um obstáculo para suas intenções de apropriação de terras e recursos e de utilização dessas pessoas como mão-de-obra barata, vivendo em condições degradantes e sob violências de diferentes formas. Há também, muito que ser feito nos campos da saúde, saneamento básico e da educação escolar. Há dados e avaliações suficientes que demonstram estarem entre as populações negras rurais os índices mais baixos em termos de escolaridade, nutrição e saneamento. Considerando os desafios, é pouco o orçamento e lamentável o gasto efetivamente realizado ${ }^{6}$.

Portanto, os problemas relatados por Verdum coadunam com as palavras de Casimiro (2010, p. 28), quando este afirma que, inúmeras vezes, as declarações de erradicação ou mesmo redução da pobreza representam apenas discursos de

[...] chefes de Estado do chamado mundo desenvolvido reiterando os seus compromissos, sem que todavia se vislumbre a sua vontade de atacar as causas sistémicas da pobreza, mas na prática apenas uma vontade das elites corporativas e políticas de manter o status quo.

Diante disso, defendemos que a sociedade civil precisa se mobilizar, do mesmo modo que instituições provedoras de pesquisa como a academia, também devem, perante responsabilidade social e ética, atuar nesses contextos de 
pobreza buscando estratégias em parceria com as populações, para a redução dos índices acima citados, e auxiliando-os no processo de libertação das opressões que, por décadas, vêm infringindo seus direitos. Freire (1983) ressalta que a generosidade verdadeira consiste na luta dos oprimidos, juntamente daqueles que verdadeiramente solidarizam-se com estes, em prol da restauração de sua humanidade. Ou seja, uma luta que faça com que as mãos de povos humildes, que antes se estendiam em gestos de súplica aos poderosos, se tornem, cada vez mais, mãos libertas a trabalharem e transformarem o mundo, escrevendo a sua vida como autoras e testemunhas de sua própria história.

Nesse sentido, apresenta-se a estratégia utilizada pelas mulheres africanas. As práticas de interajuda, ou práticas sociais de ajuda mútua, têm deixado marcas positivas na história de populações marginalizadas, inclusive elevando o continente africano a condição de primeiro continente com o maior número de mulheres no senado. Como pode ser observado nas palavras de Tripp (2013, doc. não paginado, tradução nossa) "Hoje, a África é líder na representação parlamentar das mulheres em todo o mundo [...]". Tais práticas não necessariamente foram as únicas responsáveis por esta estatística, visto que se encontram entre outras medidas políticas direcionadas aos países africanos, mas são responsáveis por importantes contribuições.

Na visão de Osório e Mejia (2006, p. 89-92), as experiências associativas representam:

[...] o surgimento de uma consciência sobre o papel das mulheres como produtoras de riqueza e maior visibilidade, num processo dinâmico de mudanças complexas e geradoras de conflitos e de novas situações também causadoras de tensões a que é necessário fazer face [...]

Foram as práticas de interajuda que lhes trouxeram independência dos orçamentos públicos que, na maioria das vezes, eram inviabilizados pela própria política de reajuste econômico para países do Terceiro Mundo, como os países africanos, onde os juros e a burocracia demasiadamente elevados obstruem o acesso aos financiamentos bancários. Logo, essas práticas, que advém da tradição e se reconfiguram ao longo das gerações, vêm auxiliando-as na manutenção e expansão das atividades associativas, resultando em significativas experiências para as mulheres pobres de países africanos, devolvendo-lhes, não só os recursos 


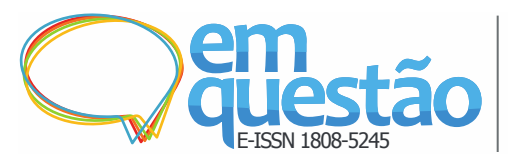

Empoderamento das mulheres quilombolas:

contribuições das práticas mediacionais desenvolvidas

na ciência da informação

Cleyciane Cássia Moreira Pereira, Jaires Oliveira Santos, Maria

Isabel De Jesus Sousa Barreira

materiais necessários para sua sobrevivência, mas também a possibilidade de acesso aos recursos políticos e sociais para suas futuras gerações. Estratégias estas que, mostrando-se viáveis após uma análise, podem ser aplicadas, com a acessória de um profissional mediador, pelas líderes quilombolas nas práticas associativas das mulheres itamatiuenses. Isso porque, como expõe Farias (2014, p. 17), “[...] o mediador deve ter em mente que estas ações devem ser realizadas sempre em conjunto e de forma dialógica com todos os sujeitos envolvidos".

\section{As associações das mulheres africanas}

As mulheres africanas adotam as práticas de interajuda/ajuda mútua desde o período pré-colonial, atribuindo-lhes um valor de tradição e, atualmente, têm inclusive ganhado força e destaque no cenário da literatura econômica. Borges e Freitas afirmam que o "[...] funcionamento de associações de mulheres está documentado nas sociedades pré-coloniais, assim como nas atuais da África Ocidental" (2005, p. 35).

Existe um número significativo de pesquisas que têm se detido sobre a forma como as mulheres africanas, tanto do espaço rural $^{7}$ quanto urbano ${ }^{8}$, têm recorrido às práticas associativas de interajuda, as quais, dependendo da localidade, recebem um nome diferente; em Moçambique, por exemplo, têm sido denominada Xitique, enquanto que em Guiné-Bissau, Abota e Mandjuandade?

É importante esclarecer que estas são práticas tradicionais retomadas e fortalecidas por mulheres pobres em meio à crise, decorrente das políticas de reajuste estrutural da década de 80 , as quais resultaram na carência de alimentos, elevaram as taxas de desemprego e aumentaram o trabalho informal. Foi a partir desse contexto que as mulheres, de diversos estados civis, foram forçadas a desenvolver trabalhos informais a fim de prover os recursos necessários para manutenção de suas famílias. Contudo, não dispondo de recursos financeiros para investir em seus negócios, recorrem às práticas associativas de ajuda mútua para obterem tais recursos através de poupanças e créditos rotativos, único meio que 
possuem para acessar a quantia necessária para investir em atividades geradoras de rendimento. Essas práticas se tornam a base para o desenvolvimento de diversas associações que, segundo Casimiro (2011), podem ser compreendidas em duas categorias: as Associações de Poupança e Crédito Acumulado (ASCAS) ${ }^{10}$, que se diferenciam das Associações de Poupança e Crédito Rotativo, as ROS$\mathrm{CAS}^{11}$, por serem mais complexas, flexíveis e por geralmente serem geridas por mulheres.

Como exposto, para que essas mulheres mantivessem suas associações, adotaram as práticas tradicionais de poupança com as mais diversas finalidades; desde adquirir poupança financeira, comprar produtos, bens e custear os estudos dos filhos, até exercer a manutenção de suas relações sociais. Para os membros dessas associações, algumas regras são estabelecidas previamente, tais como: os membros devem pertencer a grupos comuns ou suficientemente confiáveis para assegurar que cumprirão as quotizações, valores e prazos estabelecidos.

Casimiro (2010; 2011) desenvolveu sua pesquisa nas regiões da Zambézia e Sofala, em Moçambique, onde observou que, de acordo com a proveniência desses recursos (capital financeiro, bens materiais e imateriais), sendo local ou externa, as ASCAS e as ROSCAS são separadas em dois grupos: de associações endógenas e exógenas ${ }^{12}$. Em alguns momentos, as práticas associativas de poupança e de ajuda mútua (endógenas) viabilizam o pagamento dos créditos financiados por associações externas (exógenas). No entanto, quando as associações endógenas são estabelecidas, contribuem significativamente para o empoderamento das mulheres engajadas, visto que tanto os juros quanto as multas são arcados e decididos coletivamente, sem a necessidade de que estas mulheres se tornem escravas do dinheiro proveniente de instituições externas. Dessa forma, o empoderamento, compreendido como a possibilidade dessas mulheres terem autonomia sobre suas próprias decisões, além de lhes restabelecer a auto-estima, devolve sua confiança em um futuro melhor. Segundo Casimiro (2010, p. 15$16)$ :

[...] a participação das mulheres em associações por si organizadas permite-lhes adquirir não apenas recursos materiais - terra, trabalho e capital - mas também recursos políticos ou sociais acedendo aos mecanismos que lhes assegurem a continuidade do acesso aos recursos. 


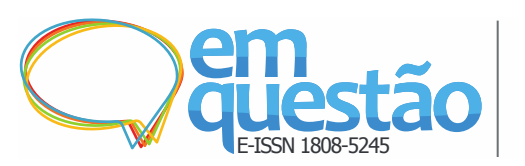

Empoderamento das mulheres quilombolas: contribuições das práticas mediacionais desenvolvidas na ciência da informação

Cleyciane Cássia Moreira Pereira, Jaires Oliveira Santos, Maria Isabel De Jesus Sousa Barreira

As associações de mulheres da Guiné-Bissau têm alcançado êxito na região urbana. São mulheres solteiras, desquitadas e até casadas, mas cujos esposos não conseguem arcar com as responsabilidades da casa devido à crise. Nessas associações elas têm recorrido a Abota e as Mandjuandades, práticas que as têm auxiliado a ampliar seus negócios e, atualmente, a expandir o número de associações que usam dessas estratégias, como a Associação das Mulheres Peixeiras (AMU-PEIXE); a Associação das Mulheres Revendedeiras de Peixe (MAVIP); a Associação das Mulheres Tintureiras de Bissau (DUA-DJABI); e a Associação das Mulheres Revendedoras do Mercado de Clelé (NUNCAFALTA) (GOMES, 2008).

O Xitique, por sua vez, tem sido mais adotado nas províncias de Sofala e Zambézia, na região rural de Moçambique. Casimiro (2010; 2011) realizou investigações com as mulheres dessas regiões no que se refere a essa prática, e percebeu nítidos progressos desencadeados por essa forma de obtenção de crédito financeiro. Segundo a fala de uma promotora ${ }^{13}$ concedida a Casimiro (2011, p. 15):

Desde que se criou o PCR [ROSCAS] a vida das pessoas está a melhorar. Há uma grande diversidade de negócios: compra de peixe, sal, milho, hortícolas para a revenda. Este crédito já fez com que conseguíssemos muita coisa. Colocámos os nossos filhos na escola, comprámos mobílias e fizemos casas [...]

As práticas de ajuda mútua em Moçambique não se reduzem apenas à poupança de crédito e fundos, mas possuem outros nomes e finalidades que se manifestam, como afirmado, nas mais diversas formas de relações sociais. Em Casimiro (2011, p. 12):

a) Kurhimela/Xitoco, Tsima/Ntimo: atividades relacionadas com o trabalho agrícola, baseadas na amizade e convivência comunitária;

b) Matsoni/Xivunga: práticas tradicionais que se baseiam na troca de mão-de-obra por mão-de-obra;

c) Thôthôtho, Kuthekela, Ganho-ganho: troca de mão-de-obra por alimentos ou dinheiro;

d) Kuvekhelissa e Ovaliha: troca de mão-de-obra pela acumulação de gado;

Contudo, alguns cuidados são pertinentes, pois, como relata a autora, há também casos de mulheres que não recorrem a essas práticas por receio de que os demais membros descumpram as regras adotadas e que, por conta disso, elas fiquem sem receber seus valores. Além disso, segundo Elson (1997), o fortale- 
cimento dessas estratégias causa outra preocupação, que se refere ao crescimento do trabalho informal e precarizado ao qual essas mulheres são submetidas devido à falta de assistência, tanto do Estado quanto dos bancos.

Entretanto, associações como o Xitique e as Abotas geram experiências mais positivas que negativas. Ao conceder poderes econômicos, políticos e sociais, possibilita que essas mulheres cheguem a cargos públicos, o que lhes dá a oportunidade de transformar suas histórias através da elaboração de leis e projetos que contribuam para caminharem em prol do empoderamento de sua classe. Borges (2005, p. 25) corrobora esta afirmação com o seguinte comentário:

Antes, como atualmente, as mulheres apelando aos valores tradicionais da solidariedade feminina e da mutualidade, organizam-se em associações para aumentarem o seu poder econômico, religioso e político, enquanto estratégias de emancipação social e política. Neste âmbito, as associações de mulheres constituem importantes espaços sociais, econômicos e afetivos, proporcionando às mulheres os meios de enfrentarem de forma autônoma os desafios e constrangimentos das suas vidas.

Esse empoderamento_é que têm lhes possibilitado desfrutar de conquistas e do reconhecimento, tanto por parte dos cientistas sociais quanto da mídia internacional, em face de suas estratégias econômicas baseadas na poupança de crédito rotativo e em suas práticas solidárias que, inclusive, lhes têm oportunizado uma representatividade feminina dentro dos espaços políticos e parlamentares cuja amplitude não possui precedentes na história mundial. De acordo com Tripp (2013), em países como a Ruanda, por exemplo, as mulheres chegam a ocupar 64\% dos assentos legislativos. Trata-se de uma realidade que ainda não abrange todo no continente africano, mas que deixa para trás inúmeros países do continente americano e europeu.

Esses são exemplos de sucesso para as mulheres das comunidades quilombolas, que também precisam dinamizar e potencializar o trabalho de suas associações para, assim, poderem da mesma forma alcançar espaços políticos e públicos, e auxiliar sua população a tecer narrativas mais positivas e prosperas. Afinal, segundo Freire (1983, p. 32), o processo de construção e libertação das classes pobres e oprimidas deve ser planejado e tecido pelos próprios oprimidos,

Quem, melhor que os oprimidos, se encontrará preparado para entender o significado terrível de uma sociedade opressora? Quem sentirá, melhor que eles, os efeitos da opressão? Quem mais do que 


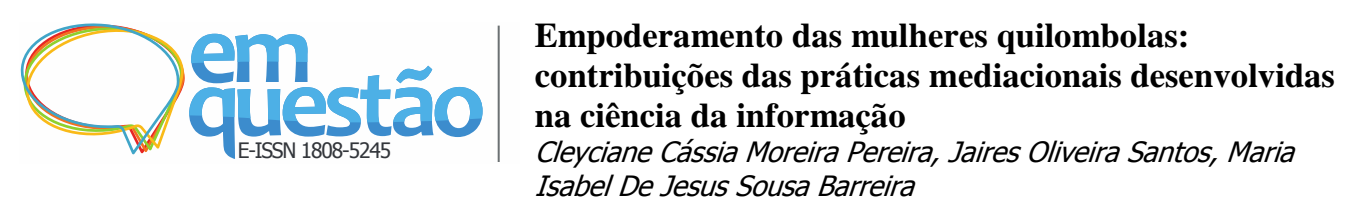

eles, para ir compreendendo a necessidade da libertação? Libertação a que não chegarão pelo acaso, mas pela práxis de sua busca; pelo conhecimento e reconhecimento da necessidade de lutar por ela [...].

\section{Associação de mulheres quilombolas de Itamatatiua}

Itamatatiua está situada no município maranhense de Alcântara. O Maranhão, sobretudo durante a Companhia Geral do Grão Pará e Maranhão ${ }^{14}$, “[...] recebeu mais de 12000 negros escravizados" (LIMA, 1981, p. 12). Vindos, segundo Meireles (1994), de cinco importantes localidades: Guiné-Bissau, Togo, Benin, Nigéria e Angola; e, em grupos menores, do Senegal, Gâmbia, Guiné, Alto Volta, Gana, Costa do Ouro, Congo, além dos arquipélagos de Cabo Verde e de São Tomé e Príncipe.

É certo que o passado dos negros escravizados no Maranhão demarca a formação do povo maranhense, manifestando-se na identidade étnica e em vários aspectos culturais. Segundo demonstrado nos dados do Censo do IBGE (2013), é o estado com um dos maiores percentuais de identificação parda do país, compreendendo cerca de $66,5 \%$ da população. Perde apenas para os estados do Pará (69,5\%) e Amazonas (68,9\%), pois nestas regiões a cor parda se dá em decorrência da "miscigenação entre brancos e índios", enquanto que no caso maranhense trata-se de afrodescendência ${ }^{15}$ (COSTA, 2013).

De acordo com Barreto (1977), ainda que o Maranhão tenha iniciado tardiamente o tráfico negreiro, em certo período apresentou-se uma percentagem mais elevada de negros do que brancos no estado. Quantitativo que se reflete no falar, na culinária, na religiosidade, na dança, na música, dentre diversas outras práticas culturais do maranhense. Lamentavelmente, ao lado dessa ancestralidade com a "Mãe África”, o "Estado tem os municípios com os mais baixos Índices de Desenvolvimento Humano Municipal (IDHM) encontrados no Brasil" (ÍNDICE..., 2013, p. 81).

O Município de Alcântara ajuda a compor essa lastimável estatística, com um IDHM de 0, 573, considerado muito baixo de acordo com o IBGE (2013). Ainda conforme dados do IBGE (2013), este município compreende uma população com 21.851 pessoas, das quais 15.452 habitam a zona rural, es- 
tando 46,21\% destes inseridos no percentual de extrema pobreza, isto é, vivendo com uma renda igual ou inferior a 70 reais mensais. Com uma expectativa de vida baixa (pessoas idosas somam apenas 11\% da população), ausência de água potável, rede de esgoto, coleta de lixo, acesso a transporte coletivo e educação. Alcântara é considerada, no cenário nacional, como o local que abriga o maior quantitativo de Comunidades Quilombolas.

A Comunidade Quilombola de Itamatatiua compõe o quadro geográfico e numérico desse quantitativo. Com mais de 300 anos. Vivem nessa comunidade 132 famílias $^{16}$, um total de 452 pessoas, sendo 44,4\% homens, 40,7\% mulheres e 14,9\% crianças e jovens. As condições sanitárias locais não destoam das demais comunidades quilombolas. Nas casas, prevalece a construção de paredes feita com uma trama de ripas ou varas cobertas de barro, conhecidas como pausa-pique, e tetos feitos de pindoba ${ }^{17}$. Em $88 \%$ das casas, o abastecimento de água é feito através de poço ou nascente; a localidade possui apenas uma escola primária, as demais séries escolares os alunos se deslocam a municípios vizinhos; inexistência de postos de saúde e serviços de coleta de lixo ${ }^{18}$.

Itamatatiua fica localizada cerca de $90 \mathrm{~km}$ de São Luís, capital do Maranhão e 70 km de Alcântara. A chegada acontece por duas vias: via ferry boat do Terminal da -Ponta da Espera (São Luís) até o Terminal do Cujupe (Alcântara), depois de ônibus até o Ramal (local que se deixa o percurso da Rodovia MA, demarcado por um grande pote de barro com a imagem da Santa Terezinha D’Ávila, e adentra-se a Comunidade), e mais vinte minutos de caminhada; ou também por lancha, saindo de São Luís até Alcântara, e então pegando um ônibus que leva à sede do povoado. À distância, no entanto, não impede que admiradores nacionais e internacionais visitem Itamatatiua, ou que pesquisadores, como antropólogos, comunicólogos, bibliotecários, designers, dentre outros, frequentemente a tomem como objeto de pesquisa. Isto justificado, além das características identitárias o reconhecimento de que seus ancestrais são escravos.

Em meio às adversidades inerentes ao contexto itamatatiuense, as mulheres quilombolas têm desenvolvido atividades como a produção de cerâmica, prática tradicional que remonta por mais de duzentos anos, provendo-lhes de uma fonte de renda que se junta à agricultura de subsistência, aposentadoria, e, 
atualmente, a benefícios provenientes de programas do Governo Federal (Bolsa Escola, Bolsa Família e outros).

A Comunidade, como mencionado, é composta por $40,7 \%$ de mulheres $^{19}$. Após a morte do senhor Eurico de Jesus ${ }^{20}$, em 1991, as mulheres vem liderando a Comunidade. Liderança que se tornou um diferencial em termos de organização social na localidade

Há de se ressaltar que o comando do gênero feminino em Itamatatiua não é recorrente em outras comunidades quilombolas de Alcântara e do Maranhão. Em diversas regiões do estado, ao contrário de Itamatatiua, são os homens que coordenam os sítios quilombolas, organizando-se social e politicamente. (REIS, 2010, p. 134).

Referindo-se a atuação das mulheres na Comunidade, Dona Canuta ${ }^{21}$ (2010) menciona: "Nós é que somos do garra, e os homens fica tudo ôh... e nós ôh é que tem que enfrentar!" (informação verbal) ${ }^{22}$. Assim, nessa fala esta Senhora reforça as atitudes de enfrentamento que as mulheres precisam assumir em relação aos homens, que em geral se acomodam, diante dos problemas e necessidades cotidianas dessas famílias e da própria Comunidade.

Conforme relatou Dona Neide, a Associação de Mulheres foi organizada há 10 anos, que é representante da Comunidade. Sua substituição ocorre através de eleição direta a cada dois anos. Cruz (2008) ressalta que a maior parte das comunidades quilombolas está organizada na forma de Associação e atua no sentido de fortalecer o processo produtivo. Amaral (2005, p. 10) afirma que:

\footnotetext{
A criação de associações vem ocorrendo principalmente através de reuniões, seminários e encontros onde as comunidades têm a oportunidade de discutir os seus problemas, trocar experiências e formular ideias. No entanto, essa organização política está em diferentes fases dependendo da comunidade, enquanto algumas estão ainda se afirmando como remanescentes de quilombos, outras já estão em processo de titulação de suas terras ou mesmos com terras já demarcadas.
}

A sede da Associação da Produção de Cerâmica foi construída com ajuda de entidades públicas e privadas, inaugurando uma fase que marca o fabrico da cerâmica na vida das itamatatiuenses, que deixam o espaço privado, suas casas, para se reunirem em um espaço coletivo que atrai públicos nacionais e internacionais para aquisição desses produtos. Tal empreendimento já rendeu a compra de um caminhão, de uma máquina para preparar o barro e confeccionar artesanato, a instalação de energia elétrica e a construção de um poço artesiano 


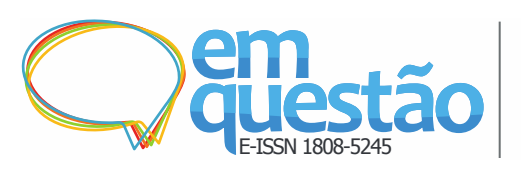

Empoderamento das mulheres quilombolas: contribuições das práticas mediacionais desenvolvidas na ciência da informação

Cleyciane Cássia Moreira Pereira, Jaires Oliveira Santos, Maria Isabel De Jesus Sousa Barreira

para o abastecimento da água nas moradias de alguns membros dessa Comunidade. Esses poucos recursos são derivados da luta diária das mulheres Itamatiuenses frente a inúmeras necessidades inerentes ao seu cotidiano. As mulheres, em grande parte, conciliam suas atividades frente à Associação com os labores domésticos, da roça, e como chefe de suas famílias.

A luta dessas mulheres, à frente da organização da Associação de Produção de Cerâmica, assemelha-se à resistência que impregna a história das mulheres africanas. Segundo Werneck (2010, p. 14):

[...] a ação política das mulheres negras nas diferentes regiões não foi novidade inaugurada pela invasão europeia e a instauração da hegemonia cristã. $\mathrm{O}$ que torna fácil compreender que tais ações precederam a criação do feminismo. No entanto, seu grau de influência sobre a criação deste ainda permanece invisível e pouco considerado.

Dessa forma, as práticas associativas são inerentes ao contexto e cotidiano das mulheres itamatatiuenses. Um exemplo dentre as práticas de interajuda com a finalidade de promover as relações sociais é a Festa de Santa Tereza D'Ávila de Jesus, considerada uma mãe pelos moradores que, em sua maioria, adotam o "de Jesus" aos seus sobrenomes, mantendo para com a Santa uma significativa devoção. A Festa acontece há mais de oito décadas, entre os dias 15 e 17 de outubro, os itamatatiuenses recebem romeiros e seus filhos, que retornam para pagar promessas.

A Festa consiste numa tradição em que todos os moradores se reúnem com o propósito de ofertar um merecido festejo à Santa e, ao mesmo tempo, oferecer um farto banquete com comidas e bebidas a todos que chegam. A união resulta em meses de preparação, onde as senhoras chamadas caixeiras saem recolhendo jóias ${ }^{23}$ nas localidades vizinhas a fim de levantar fundos para custear as despesas com a Festa.

Outro momento, em que as práticas de interajuda podem ser visualizadas apresenta-se nas trocas de dias na roça. Segundo Pereira Junior (2012, p. 28):

A troca de dia acontece na comunidade entre lavradores que, na maioria das vezes possuem relações sociais bastante estreitas, tais como: parentesco, compadrio e outras relações de afinidades. Eles formulam uma espécie de contrato tácito que envolve o trabalho na roça de ambos, através do dispositivo de troca de dias. No caso de dois irmãos, por exemplo: João e José, se João for capinar sua roça José oferece um dia de serviço a João (José dá um dia de serviço a 
Durante a construção de uma casa é também recorrente que vizinhos se ajudem, unindo forças na execução de trabalhos cotidianos. A exemplo, naquelas cuja construção se dê nas formas tradicionais (taipa e sapê), pessoas que ajudam recebem como agrado bebidas e, ou comida.

Como apontado anteriormente, é possível identificar atividades associativas e práticas de interajuda que precisam ser aprofundadas in loco, visto que são informações decorrentes da pesquisa de mestrado. Nesse período, nosso objeto de investigação perpassava também pelo prisma das narrativas e elementos iconográficos pertencentes aquele contexto, porém sentimos a necessidade sobretudo de aprofundar a investigação de como ocorre a junção de fundos para o mantimento das atividades associativas das mulheres itamatatiuenses. Posteriormente, tais conhecimentos poderiam ser expostos através de seminários, de conversas informais nas próximas oportunidades que estivermos em campo e, assim, se tornarem "as informações" que virão a ser trabalhas pelo empoderamento dessas mulheres na dinamização das suas atividades associativas.

Por outro lado, as atividades associativas das mulheres africanas reforçam um olhar através do qual podemos focar nossas ações e nossa capacidade de identificar as necessidades informacionais das Comunidades Quilombolas para que possamos, em parceria com as mulheres itamatiuenses, dialogar com os conceitos de Ciências da Informação (CI) e desenvolver uma proposta de mediação informacional a partir da pesquisa-ação ${ }^{24}$.

\section{Reflexão sobre a mediação da informação para comunidades quilom- bolas}

Para Wersig e Nevelling (1975), renomados teóricos da CI, transmitir informação para todos que dela necessitam é uma responsabilidade social, sendo esse, ao que tudo indica, o verdadeiro propósito desta área.

Recentemente, durante o XXV Congresso Brasileiro de Biblioteconomia, Documentação e Ciência da Informação (CBBD/FEBAB), um importante evento da área realizado no ano de 2013, também chamou a atenção para essa res- 
ponsabilidade social dos profissionais da informação (bibliotecários, museólogos, arquivistas, cientistas da informação e afins), que deveriam atuar para além dos espaços instituídos (como bibliotecas, museus, arquivos e centros de documentação) e caminhar, sobretudo, ao encontro das populações vulneráveis,

[...] entendidas como sendo aquelas que se encontram em situações de discriminação, intolerância e fragilidade e que estão em desigualdade e desvantagem na sociedade atual, principalmente, em relação às questões que envolvem o acesso e uso da informação para a construção de conhecimento, identidade e autonomia a fim de permitir a sua efetiva inclusão social. (MANIFESTO..., 2013, p. 1, grifo nosso).

Populações vulneráveis que compreendemos também como comunidades pobres, marginalizadas e renegadas pelas mais variadas formas de exclusão social. Freire (2001) menciona que o papel do profissional da CI frente a comunidades que experimentam formas de exclusão, principalmente aquelas privadas de várias modalidades de informação, é disseminar a informação de modo a delinear-lhes um caminho para a inclusão social de forma mediacional. Inclusão social que pode ser percebida como o empoderamento que essas populações têm, então, a possibilidade de construir através da apropriação da informação, precisa e pontual, em suas realidades.

Significativas pesquisas na CI têm sido empreendidas nesse sentido, como os estudos realizados por Farias (2014), que trabalhou com a mediação da informação em duas comunidades urbanas à margem das condições mínimas de cidadania, localizadas em João Pessoa (PB) e em Rione Sanità (Itália). Nessa pesquisa, embasada pelos conceitos de CI, o autor demonstrou que é possível auxiliar no processo de empoderamento de uma comunidade a partir de um modelo de mediação da informação, que, por sua vez, é compreendida como:

[...] toda ação de interferência - realizada pelo profissional da informação -, direta ou indireta; consciente ou inconsciente; singular ou plural; individual ou coletiva; que propicia a apropriação de informação que satisfaça, plena ou parcialmente, uma necessidade informacional. (ALMEIDA JUNIOR, 2009, p. 92).

Assim, a mediação requer algumas reflexões dos profissionais da informação no que se refere aos usuários, tais como: quais informações eles necessitam; quais fontes informacionais são mais pertinentes para contemplar suas necessidades; quais os conhecimentos necessários; como abordá-los, lembrando sempre que 


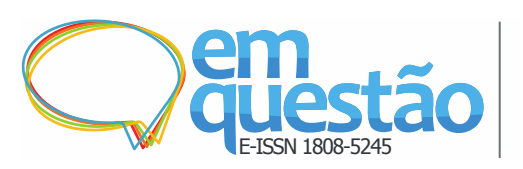

Empoderamento das mulheres quilombolas: contribuições das práticas mediacionais desenvolvidas na ciência da informação

Cleyciane Cássia Moreira Pereira, Jaires Oliveira Santos, Maria Isabel De Jesus Sousa Barreira

estes são dotados de saberes e valores prévios que não podem ser desconsiderados no processo de mediação da informação. Visto que, a efetivação desse processo pode resultar no desenvolvimento de competências em informação que fariam de seus usuários, atores na busca e na identificação de informações confiáveis e relevantes para suas necessidades pessoais e profissionais.

Segundo Melo e Araújo “[...] o conceito de competência em informação está diretamente relacionado às atitudes que facilitam criar e compartilhar o conhecimento, ou seja, com o aprendizado ao longo da vida (lifelong learning)" (2007, p. 199).

O lifelong learning é intenciona, quer formalmente gerenciado ou autogerenciado é essencial para o sucesso na Sociedade da Informação, devido às mudanças rápidas que ocorrem neste contexto. A competência a informacional é um pré-requisito e um habilitador essencial para o lifelong learning, além de também estar em entrelaçado intimamente com a cidadania participativa (MELO; ARAÚJO, 2007, p. 199).

Melo e Araújo (2007, p. 187) enfatizam uma mudança de enfoque na Sociedade da Informação que supera o "gerencial", no qual se valorizava o acúmulo de conhecimento para a qualidade do aprendizado, isto é, “[...] o quanto se é capaz de aprender através de informações diversificadas e contextualizadas e de se aplicar o conhecimento resultante do acesso e uso de tais informações". Dentro desse contexto, considera-se que a competência em informação venha inclusive possibilitar a construção de uma identidade mais fortalecida e, ao mesmo tempo, um engajamento político e social mais consciente. Farias e Varela (2012, p. 14) mencionam que:

[...] as crenças que a comunidade, a sociedade, o mediador e a pessoa (os moradores) podem construir por meio do processo de mediação com visão inclusiva, tendo como pressupostos a identidade social que cada ser deveria ter de si próprio, da realidade que o cerca e que ele próprio pode melhorar, quebrando as barreiras de preconceitos construídos pelo processo de exclusão, de estar à margem.

Assim, seguimos cientes de que trabalhar pelo empoderamento e protagonismo social das mulheres quilombolas por meio de atividades associativas mostra-se um desafio enorme, porém necessário, diante do levantamento do MDS sobre as comunidades quilombolas que evidenciou dentre suas carências inclui-se a informacional. Temos também a convicção de que, apesar do arca- 


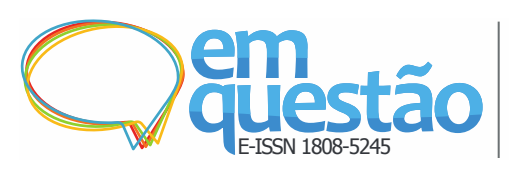

Empoderamento das mulheres quilombolas:

contribuições das práticas mediacionais desenvolvidas

na ciência da informação

Cleyciane Cássia Moreira Pereira, Jaires Oliveira Santos, Maria

Isabel De Jesus Sousa Barreira

bouço teórico e prático da CI não ser suficiente mediante os bolsões de pobreza que engloba as populações quilombolas, estes ainda podem auxiliar no desenvolvimento de competências humanas e informacionais necessárias a partir da mediação informacional.

\section{Considerações finais}

As estratégias encontradas pelas mulheres africanas frente à pobreza, como a poupança de crédito rotativo, constituem exemplos que poderão ser adequadas e adotadas (e fortalecer) as práticas associativas das mulheres quilombolas a partir da mediação informacional. No entanto, é importante considerar a possibilidade de aprendizado com as lideranças das mulheres quilombolas, as quais podem apresentar estratégias peculiares e díspares que podem ser replicadas em outros contextos de pobreza no território nacional.

Assim, com o fortalecimento das atividades associativas a partir das lideranças quilombolas, valores como a confiança e auto-estima geralmente negados pelos processo de exclusão poderão ser retomados e desenvolvidos. Nesse sentido, os profissionais da informação e os conceitos de CI podem auxiliar as populações pobres e marginalizadas a caminharem ao encontro de um empoderamento que lhes permita fazer suas próprias escolhas - desvinculadas das vontades e tiranias dos opressores - e atuar na elaboração das leis, políticas educacionais e sociais que correspondem a suas realidades.

Dessa forma, empoderar essas mulheres a partir da mediação da informação consiste em desenvolver habilidades, atitudes e comportamentos informacionais que as conscientizem de sua força e poder diante de suas próprias narrativas, e ajudá-las a assumir a parte prosaica e poética de suas vidas, muitas vezes usurpadas pelas desesperanças que as acometem por falta de informação.

Para que o processo de mediação da informação ocorra, o profissional da informação (profissional mediador) precisa desenvolver competências técnicas e informacionais necessárias para tal atuação. Não obstante, de maneira generosa, mas como um profissional capacitado para orientar e buscar interdisciplinarida- 


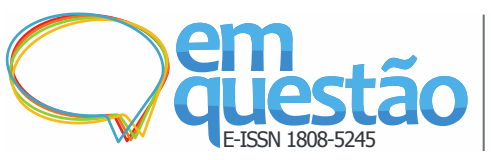

de, com as diferentes áreas e saberes, na construção de teias informações que conduzam ao empoderamento da população envolvida.

\section{Referências}

ALMEIDA JÚNIOR, O. F. de. Mediação da informação e múltiplas linguagens. Pesquisa Brasileira em Ciência da Informação, Brasília, v. 2, n. 1, p. 89-103, jan./dez. 2009.

AMARAL, A. J. P. Etnologia, educação e ambiente nos quilombos da Amazônia. Belém: Mimeo, 2005.

BARRETO, M. A. P. Os voduns do Maranhão. São Luís: Fundação Cultural do Maranhão,

1977.

BORGES, M. E. As mulheres em África: dinâmicas informais de socialização, educação, reprodução e inovação cultural. Revista Educação em Questão, Natal, v. 22, n. 8, p. 7-33, jan./abr. 2005.

BORGES, M. E.; FREITAS, J. M. Perspectivas histórico-educacionais do associativismo feminino na África e no Brasil - memórias solidárias: Mandjuandades na Guiné-Bissau e a Irmandade da Boa Morte na Bahia. Revista Educação em Questão, Natal, v. 22, n. 8, p. 34-54, jan./abr. 2005.

BRASIL. Constituição (1988). Constituição da República Federativa do Brasil: texto constitucional promulgado em 5 de outubro de 1988, com as alterações determinadas pelas Emendas Constitucionais de Revisão no 1 a 6/94, pelas Emendas Constituicionais $\mathrm{n}^{\circ} 1 / 92$ a 76/2013 e pelo Decreto Legislativo $\mathrm{n}^{\circ}$ 186/2008. Brasília, DF: Senado Federal, 2014.

BRASIL. Secretaria de políticas de promoção da igualdade racial. Guia de políticas públicas para comunidades quilombolas. Brasília: SEPPIR, 2013.

CASIMIRO, I. M. Empoderamento económico da mulher, movimento associativo e acesso a fundos de desenvolvimento local. Maputo: Centro de Estudos Africanos, Universidade Eduardo Mondlane, 2010.

CASIMIRO, I. M. Mulheres em actividades geradoras de rendimentos: experiências de Moçambique. Évora, 2011. Disponível em: <http://www.cisaas.uevora.pt/download/EncontrosEmpreendedorismo/Artigo\%20de\%20Isabel\% 20Maria\%20Casimiro.pdf >. Acesso em: 20 set. 2014. 


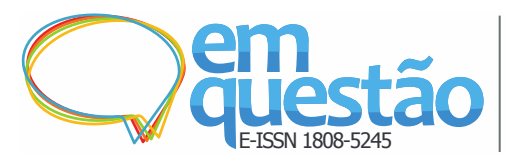

Empoderamento das mulheres quilombolas: contribuições das práticas mediacionais desenvolvidas na ciência da informação

Cleyciane Cássia Moreira Pereira, Jaires Oliveira Santos, Maria Isabel De Jesus Sousa Barreira

CASIMIRO, I. M. Paz na terra, guerra em casa: feminismo e organizações de mulheres em Moçambique. 1999. 262 f. Dissertação (Mestrado em Sociologia) Faculdade de Economia, Universidade de Coimbra, Coimbra, 2003.

COSTA, F. Pará tem maior percentual dos que se declaram pretos ou pardos, diz estudo. G1, Brasília, 05. nov. 2013. Disponível em:

<http://g1.globo.com/brasil/noticia/2013/11/para-tem-maior-percentual-dos-quese-declaram-pretos-ou-pardos-diz-estudo.html >. Acesso em: 10 jan. 2015.

CRUZ, K. C. M. dos S. O papel da educação do campo na construção do desenvolvimento rural: uma proposta de agenda para a pesquisa a partir das dimensões de gênero e raça na agricultura familiar. In: CONGRESSO DA SOCIEDADE BRASILEIRA DE ECONOMIA, ADMINISTRAÇÃO E SOCIOLOGIA RURAL. 46., 2008, Rio Branco. Anais... Rio Branco: Sober, 2008. Disponível em: 〈http://www.sober.org.br/palestra/9/605.pdf >. Acesso em: 12 fev. 2015.

ELSON, D. Gender Analysis and Economic in the context of Africa. In: IMAM, A.; MAMA, A.; SOW, F. (Ed.). Engendering African Social Sciences. Dakar: CODESRIA, 1997.

FARIAS, M. G. G. Análise da produção, implementação e avaliação de um modelo de mediação da informação no contexto de uma comunidade urbana. 2014. 296 f. Tese (Doutorado em Ciência da Informação) - Programa de Pós-graduação em Ciência da Informação, Universidade Federal da Bahia, Salvador, 2014.

FARIAS, M. G. G.; VARELA, A. V. Desenvolvimento de competências informacionais em moradores de uma comunidade popular urbana. In: ENCONTRO NACIONAL DE PESQUISA EM CIÊNCIA DA INFORMAÇÃO. 13., 2012, Rio de Janeiro. Anais... Rio de Janeiro: Fiocruz, 2012. Disponível em: <http://competenciainformacional.files.wordpress.com/2013/03/enancib2012c.pdf >. Acesso em: 10. fev. 2015.

FREIRE, I. M. A responsabilidade social da ciência da informação e/ou O olhar da consciência possível sobre o campo científico. 2001. 166 f. Tese (Doutorado em Ciência da Informação) - Instituto Brasileiro de Informação em Ciência e Tecnologia; Universidade Federal do Rio de Janeiro, Rio de Janeiro, 2001.

FREIRE, P. Pedagogia do oprimido. 12. ed. Rio de Janeiro: Paz e Terra, 1983.

FUNDAÇÃO CULTURAL PALMARES. Quadro geral de comunidades remanescentes de quilombolas. Brasília, 2015. Disponível em:

$<$ http://www.palmares.gov.br/wp-content/uploads/crqs/quadro-geral-por-estadoate-23-02-2015.pdf $>$. Acesso em: 7 jun. 2015.

ÍNDICE de desenvolvimento humano municipal brasileiro. Brasília: PNUD; Ipea; FJP, 2013. 
INSTITUTO BRASILEIRO DE GEOGRAFIA E ESTATÍSTICA. Atlas do censo demográfico 2010. Rio de Janeiro: IBGE, 2013. Disponível em:

<http://biblioteca.ibge.gov.br/index.php/bibliotecacatalogo?view=detalhes\&id=264529> . Acesso em: 12 fev. 2015.

GOMES, P. G. As mulheres do sector informal: experiências da Guiné-Bissau. Évora, 2008. Disponível em: $<$ http://www.cisaas.uevora.pt/download/EncontrosEmpreendedorismo/Artigo\%20de\%20Patricia \%20Gomes.pdf>. Acesso em: 20 nov. 2014.

GRIJÓ, W. P. Mediações quilombolas: apropriações étnicas na recepção de telenovelas. 2014. 285 f. Tese (Doutorado em Comunicação e Informação) Pós-graduação em Comunicação e Informação, Universidade Federal do Rio Grande do Sul, Porto Alegre, 2014.

GUERRA, L. H. Memória e etnicidade no Quilombo Ilê Axé Oyá Meguê. Ciências Sociais Unisinos, São Leopoldo, v. 47, n. 3, p. 284-291, set./dez. 2011.

LIMA, O. C. A casa de nagô, tradição religiosa ioruba no Maranhão. São Luís: UFMA/Corsup, 1981.

MANIFESTO de Florianópolis sobre a competência em informação e as populações vulneráveis e minorias. Infohome. [S.1.]: 2013. Disponível em: <http://www.ofaj.com.br/textos_conteudo.php?cod=478>. Acesso em: 5 jan. 2015.

MEIRELES, M. M. Dez estudos históricos. São Luís: Alumar, 1994.

MELO, A. V. C.; ARAÚJO, E. A. Competência informacional e gestão do conhecimento: uma relação necessária no contexto da sociedade da informação. Perspectivas em Ciência da Informação, Belo Horizonte, v. 12, n. 2, p. 185201, maio/ago. 2007. Disponível em:

<http://portaldeperiodicos.eci.ufmg.br/index.php/pci/article/view/49>. Acesso em: 14 jan. 2015.

MELO NETO, J. F. de. Pesquisa-ação: aspectos práticos da pesquisa-ação nos movimentos sociais populares e em extensão popular. [2005?]. Disponível em: $<$ http://www.prac.ufpb.br/copac/extelar/producao_academica/artigos/pa_a_pesq uisa_acao.pdf $>$. Acesso em: 5 fev. 2010.

OLIVEIRA, F. M. B. de. Mobilizando oportunidades: estado, ação coletiva e o recente movimento social quilombola. 2009. 237 f. Dissertação (Mestrado em Ciência Política) - Programa de Pós-graduação em Ciência Política, Faculdade de Filosofia, Letras e Ciências Humanas, Universidade de São Paulo, São Paulo, 2009. 
OSÓRIO, C.; MEJIA, M. As relações sociais de poder: um estudo nas províncias de Inhambane e Nampula. Maputo, Moçambique: CARE Internacional, 2006.

PEREIRA, C. C. M. Mitos da cultura africana: elementos de informação e preservação da memória na Comunidade Quilombola Alcantarense de Itamatatiua. 2011. 127 f. Dissertação (Mestrado em Ciência da Informação) - Programa de Pós-graduação em Ciência da Informação, Universidade Federal da Paraíba, João Pessoa, 2011.

PEREIRA JÚNIOR, D. Territorialidades e identidades coletivas: uma etnografia de Terra de Santa na Baixada maranhense. 2012. 151 f. Dissertação (Mestrado em Antropologia) - Programa de Pós-Graduação em Antropologia, Universidade Federal da Bahia, Salvador, 2012.

REIS, M. G. O. Filhos da santa, terras de negro numa arqueologia quilombola: as dinâmicas de um território chamado Itamatatiua. 190 f. 2010. Dissertação (Mestrado em Arqueologia Pré-Histórica e Arte Rupestre) - Instituto Politécnico de Tomar, Universidade de Trás-os-Montes e Alto Douro, Portugal, 2010 .

SANTOS, J. B. dos. O conceito de quilombos: distância entre a academia e os quilombolas. Investidura. Florianópolis, 2011. Disponível em: $<$ http://www.investidura.com.br/biblioteca-juridica/artigos/ historia-dodireito/4023-o-conceito-de-quilombos-distancia-entre-a-academia-e-osquilombolas.html>. Acesso em: 10 jan. 2015.

SUMÁRIO executivo: pesquisa de avaliação da situação de segurança alimentar e nutricional em comunidades quilombolas tituladas. Brasília: FEC-UFF; DataUFF, 2013.

THIOLLENT, M. Pesquisa-ação nas organizações. São Paulo: Atlas, 1997.

TRIPP, A. M. Women and politics in Africa today. Democracy in África, [S.1.], 2013. Disponível em: <http://democracyinafrica.org/women-politicsafrica-today/>. Acesso em: 10 jan. 2015.

WERNECK, J. Nossos passos vêm de longe! Movimentos de mulheres negras e estratégias políticas contra o sexismo e o racismo. Revista da ABPN, [Florianópolis], v. 1, n. 1, p. 18-27, mar./jun. 2010. Disponível em:

$<$ https://abpn1.websiteseguro.com/Revista/index.php/edicoes/article/view/20/10 >. Acesso em: 24 jan. 2015.

WERSIG, G.; NEVELING, U. The phenomena of interest to information science. The Information Scientist, Pennsylvania, v. 9, n. 4, 1975. 


\title{
Empowerment of women quilombolas: contributions of practices mediational developed in Information Science
}

\begin{abstract}
Tthe mediacional mediation process of the that takes place within Quilombo's Communities is as facilitator facilitate for the process of social inclusion. In this work, we have covered not only the Comprise associative activities of Quilombola's women from Itamatatiua, but also and how practices of African mutual aids are present in the social relations of the itamatatiuense population, considering in response to the recurring political and economic barriers in her their lives. This study is a review of literature review and this apprehension led to a consensus that the process mediation process of mediation of information, which is a object of study of Information Science, can support empowerment and the development of persons, and persons most conscious people awareness of their own strength and un the performance for their power to take actions toward social inclusion, as well as contributing to the social protagonism of these marginalized communities.
\end{abstract}

Keywords: Information Science. Mediation of information. Social responsibility. Quilombo's Communities. Associative practices.

Recebido em: 01/07/2015

Aceito em: 20/10/2015

${ }^{1}$ Práticas associativas compreendidas a partir da expressão "associativismo" que, segundo Casimiro (2010), designa, por um lado, a prática social da criação e gestão das associações (organizações providas de autonomia e de órgãos de gestão democrática, também designados órgãos sociais: assembleia geral, direcção, conselho fiscal) e, por outro lado, a defesa dessa prática de associação enquanto processo não lucrativo de livre organização de pessoas (sócios) para a obtenção de finalidades de interesse comuns. Pode ser entendido como uma forma de organização em permanente integração, que tem como propósito conseguir benefícios comuns através de ações coletivas. Para muitas pessoas, a associação constitui a única forma de ter acesso a recursos, bens, fundos e também de ação social.

${ }^{2} \mathrm{O}$ poder de escolher, de ter autonomia, equaciona a possibilidade ou não que as mulheres têm de tomada de decisões, enquanto mulheres, com direitos e deveres, na família, na comunidade, ou sociedade. Define, por isso, um caminho próprio, e não imposto, que reconheça e respeite os direitos das mulheres no seu processo de procura de melhores condições de vida para si, para as suas famílias ou comunidades. A capacidade para definir o seu próprio caminho, tomar as suas próprias decisões, reconhecendo e respeitando os direitos dos outros, num processo de procura de melhores condições de vida para as mulheres, para os homens, as famílias e as comunidades [...]. (CASIMIRO, 2010, p. 26). 
${ }^{3}$ Dissertação intitulada Mitos da cultura africana: elementos de informação e preservação da memória na Comunidade Quilombola Alcantarense de Itamatatiua (PEREIRA, 2011), na qual analisamos e identificamos os mitos da cultura africana, considerando-os como elementos de informação e preservação na memória dessa Comunidade Quilombola, localizada em terras maranhenses.

${ }^{4}$ A primeira comunidade quilombola urbana reconhecida foi a Comunidade Família Silva, de Porto Alegre (RS), em 2004. Conferir trabalhos de Guerra (2011) e Grijó (2014).

${ }^{5}$ Há ainda uma imprecisão no que se refere ao quantitativo real das Comunidades Quilombolas. Para Fundação Cultural (2015) existem 2.474, para Oliveira (2009) são 3.545 e Seppir (Brasil, [2013?]) aponta 3.524. Diante dessa imprecisão se faz necessário o desenvolvimento de outros estudos para que possam retratar com mais fidedignidade a quantificação das Comunidades Quilombolas brasileiras.

${ }^{6}$ Entrevista concedida por Ricardo Verdum, Assessor de Políticas Socioambientais Instituto de Estudos Socioeconômicos em a Associação Contas Abertas em 2001. Disponível em: <http://www.inesc.org.br/biblioteca/textos/Sobre\%20o\%20orcamento\%20quilombola.pdf>. Acesso em: 10 jan. 2015.

${ }^{7}$ Pesquisas sobre a práticas associativas podem ser encontradas nos trabalhos da africana Isabel Casimiro (2010, 2011) pesquisadora do Centro de Estudos Africanos da Universidade Eduardo Mondlane (CEA/UEM) que realizou estudos dessas práticas entre as mulheres da região da Zambézia e Sofala, em Moçambique.

${ }^{8}$ Pesquisas como a da professora Patrícia Gomes (2008), onde destaca a experiência das mulheres de Guiné-Bissau no trabalho informal desenvolvido através das associações de atividades de poupança de crédito rotativo.

${ }^{9}$ Requer esclarecimento, segundo Van Der Vaeren (1996) a Abota, é quando o consorcio se estabelece com finalidade de ganhos pecuniários de poupança. Ao passo que a Mandjuandade é uma associação com membros que se unem com o propósito de realizar atividades para cerimoniais religiosas e/ou outras de fins lúdicos e de solidariedade social. (BORGES, 2005).

${ }^{10}$ As ASCAS têm algumas, tais como: i) as poupanças podem ser fixas ou variáveis; ii) não há obrigatoriedade de aceder ao crédito disponível por parte de cada membro, sendo este apenas atribuído aos membros que o solicitarem; iii) muitas vezes há um fundo disponível para qualquer eventualidade, desastre, alguma forma de seguro (CASIMIRO, 2011).

${ }^{11}$ ROSAS ou PCR são constituídas por um grupo de indivíduos que fazem contribuições regulares para um fundo comum, que é então emprestado na sua totalidade a um dos membros em cada ciclo dando a esse membro a possibilidade de aceder a uma grande quantidade de capital que doutro modo não seria possível. Existem em várias partes do mundo tendo designações diferentes, como por exemplo, Tontines, na África Ocidental, Xitique em Moçambique (CASIMIRO, 2010)

${ }^{12}$ As associações endógenas são aquelas que se mantem com as poupanças das ROSCAS e ASCAS, ou seja, sem recursos externos, desenvolvem-se para suprir os anseios dos próprios moradores, fortalecendo valores e tradições locais, resultando em melhorias da qualidade de vida em todos os aspectos. As associações exógenas são decorrentes de recursos e iniciativas exteriores à comunidade, em geral sem discussão das necessidades reais dos membros envolvidos, tais como as provenientes de créditos facilitados pelo governo, como os Orçamento de Investimento de Iniciativa Local (OIIL), durante a pesquisa realizada por Casimiro $(2010 ; 2011)$, menos de $10 \%$ recorreram a estes créditos.

${ }^{13}$ Técnico responsável pela formação do grupo que atua repassando as normas necessárias para o transcorrer das associações. 
${ }^{14}$ Empresa criada em 1755, pelo Marquês de Pombal, Portugal. A qual tinha como propósito o controle e fomento da atividade comercial com o Estado do Grão-Pará e Maranhão, fortalecendo a prática do mercantilismo no reino.

${ }^{15}$ Entendido como descendência africana.

${ }^{16}$ Quantidade fornecida em 2010 pela Agente de Saúde da Comunidade.

${ }^{17}$ É o nome popular de uma espécie de palmeira, nativa do nordeste brasileiro.

${ }^{18}$ Dados obtidos em 2010 pela Agente de Saúde da Comunidade.

${ }^{19}$ Dados fornecidos em 2010, pela Agente de Saúde da Comunidade.

${ }^{20}$ Pai das quatro mulheres que ocupavam a função de lideranças da Comunidade no período da coleta de dados, em 2010. O Senhor Eurico de Jesus faleceu em 1990. Foi o último líder da Comunidade antes de suas filhas assumirem.

${ }^{21}$ Canuta Sebastiana dos Santos, mulher da comunidade, nascida em 1953. Aposentada, trabalha com a cerâmica desde os 12 anos e a agricultura de subsistência.

${ }^{22}$ Entrevista concedida à pesquisadora por Dona Canuta, em Itamatatiua, em janeiro de 2010.

${ }^{23}$ Recursos financeiros, mas também ovos, os produtos que possam contribuir com a Festa.

${ }^{24}$ De acordo com Melo Neto ([2005?]), esse tipo de pesquisa estimula a participação das pessoas envolvidas com o problema e abre o seu universo de respostas, passa pelas condições de trabalho e vida da comunidade. Já para Thiollent (1997, p. 15), a pesquisa-ação "[...] consiste essencialmente em acoplar pesquisa e ação em um processo, no qual os atores implicados participam, junto com os pesquisadores, para chegarem interativamente a elucidar a realidade em que estão inseridos". 